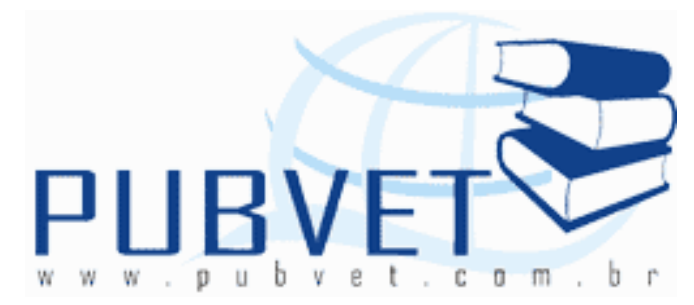

PUBVET, Publicações em Medicina Veterinária e Zootecnia.

\title{
A importância nutricional da glutamina na fisiologia de matrizes suínas lactantes
}

Rafael Santos de Aquino ${ }^{1}$, Wilson Moreira Dutra Júnior ${ }^{2}$, Helena Emília Cavacante C. C. Manso ${ }^{2}$, Hélio Cordeiro Manso Filho ${ }^{2}$, Tetty Cavalcanti Xavier ${ }^{3}$, Almir Ferreira da Silva ${ }^{3}$, Júlia da Silva Barros ${ }^{3}$, Joyci Torres D'Paula ${ }^{4}$, Telga Lucena Alves Craveiro de Almeida ${ }^{4}$

${ }^{1}$ Professor de Zootecnia e Bioquímica MSc. do Instituto Federal do Sertão Pernambucano (IFSPE), Campus Ouricuri. Estrada do Tamboril, s/no, Renascença, Ouricuri, Pernambuco, Brasil.

2 Professor Dr. do Departamento de Zootecnia, Campus Recife, Universidade Federal Rural de Pernambuco (UFRPE), Rua Dom Manoel de Medeiros s/no, CEP: 52.171-900, Recife, Pernambuco, Brasil.

3 Estudantes de Mestrado Departamento de Zootecnia, Campus Recife, Universidade Federal Rural de Pernambuco (UFRPE).

4 Estudantes de Mestrado Departamento de Veterinária, Campus Recife, Universidade Federal Rural de Pernambuco (UFRPE).

\section{Resumo}

Os aminoácidos têm despertado grande atenção nos estudos fisiológicos atualmente, por proporcionarem melhores estratégias nutricionais que potencializam a saúde, desenvolvimento e produção dos animais domésticos. Dentre tantos aminoácidos, a glutamina, vem sendo utilizada na produção 
animal e inclusive na saúde humana com base nas comprovações científicas. Considerando a fase de maternidade uma das mais sensíveis às perdas produtivas, objetiva-se apresentar a importância nutricional da glutamina, de maneira a diminuir as perdas através da redução do catabolismo corpóreo causado pelo aleitamento, a melhoria da qualidade do colostro e do leite, a manutenção de uma boa performance reprodutiva, o fortalecimento do sistema imunológico e conseqüente melhoria no desenvolvimento da leitegada.

Palavras-chave: aminoácido, lactação, porcas, suinocultura.

\title{
The nutritional importance of glutamine in the lactating sows physiology
}

\begin{abstract}
Amino acids have attracted great attention in physiological studies today by offering better nutritional strategies that enhance the health, development and production of domestic animals. Among many amino acids, glutamine, has been used in livestock and even human health based on scientifics evidences. Considering the phase of motherhood one of the most sensitive to production losses, we report the nutritional importance of glutamine in order to reduce losses by reducing the body catabolism caused by lactation phase, improving the quality of colostrum and milk, maintaining good reproductive performance, strengthening the immune system and consequent improvement in the development of the litter.
\end{abstract}

Keywords: amino acid, lactation, sows, swine production.

\section{INTRODUÇÃO}

Na suinocultura moderna, bem como na produção animal, a nutrição, com base na dieta aminoacídica, vem desempenhando importante papel de potencialização produtiva comprovada cientificamente através do uso de aminoácidos essenciais e não-essenciais nas dietas animais a fim de melhorar 
as condições fisiológicas e consequentemente produtivas. Inclusive, com a percepção de funções fisiológicas distintas entre os aminoácidos, atualmente, a classificação destes nutrientes não se restringe apenas ao grupo dos Essenciais ou Indispensáveis (aqueles indispensáveis na dieta) e aos Não-Essenciais (são aqueles dispensáveis na dieta, devido sua síntese no organismo animal), mas também como: Condicionalmente Essenciais, que são aqueles, onde, em determinado estágio fisiológico não são sintetizados em quantidade suficiente para suprir as necessidades, fazendo-se necessários na dieta (WATFORD, 2008; ABREU et al. 2010; WATFORD, et al. 2011); os aminoácidos funcionais, definidos como aqueles que possuem ação direta sobre as funções fisiológicas, melhorando o desempenho produtivo, crescimento, lactação e reprodução dos organismos e está compreendido por todos os aminoácidos essenciais e os condicionalmente essenciais (KIM, et al. 2007; WU, 2010); e os aminoácidos da Família da Arginina, que formados pela glutamina, glutamato, aspartato, asparagina, ortinita, citrulina e arginina que são metabolicamente interconversíveis em muitos mamíferos (WU, 2007).

Com base nestas novas classificações dos aminoácidos o United States Department of Agriculture in Report Dietary Guideline Advisory Comittees (USDA - DGAC, 2010) agrupou os aminoácidos da seguinte maneira: Aminoácidos Essenciais ou Indispensáveis (Histidina, Isoleucina, Leucina, Lisina, Metionina, Fenilalanina, Treonina, Triptofano e Valina), Aminoácidos Condicionalmente Essenciais (Arginina, Cisteína, Glutamina, Glicina, Prolina e Tirosina), Aminoácidos Não-essenciais ou Dispensáveis (Alanina, Ácido Aspártico, Asparagina, Ácido Glutâmico e Serina).

Nos recentes anos tem-se aumentado as atenções para a importância dos nutrientes, particularmente dos aminoácidos, na lactação e no funcionamento da glândula mamária em porcas (KIM e WU, 2009), principalmente a glutamina que é efetiva no aumento da produção de leite em porcas lactantes (WU, 2010) e também devido a sua grande atuação metabólica que evidencia benefícios ao sistema imunológico, digestório e na manutenção da massa corporal em estágios fisiológicos catabólicos como a 
gestação e lactação (WATFORD, 2008; ROTH, 2008; WU, 2010; MANSO, et al. 2012).

Esta revisão objetiva esclarecer sobre o metabolismo da glutamina e, consequentemente, a importância da suplementação de glutamina para matrizes suínas durante a lactação.

\section{O estudo histórico da glutamina}

HLASIWETZ e HABERMANN foram os primeiros cientistas a considerar a glutamina uma molécula com propriedades biologicamente importantes, em 1873. Posteriormente, novas observações levaram os pesquisadores a pensar que a amônia encontrada em hidrolisados protéicos poderia ser o resultado da liberação de glutamina, bem como de asparagina. Em 1935, cerca de 60 anos depois, KREBS, demonstrou que células possuem a capacidade de sintetizar ou degradar glutamina. Foi o início dos indícios de que a glutamina possuia uma importância nos processos bioquímicos e fisiológicos, maior do que se imaginava.

Diversos trabalhos foram executados com diversos tipos celulares, como linfócitos, macrófagos, enterócitos, entre outros, com a finalidade de se testar a utilização da glutamina pelas células, mostrando que a manutenção das estruturas e funções das células, bem como o aumento da proliferação celular, puderam ser obtidos com a utilização da glutamina em meios de cultura (CALDER \& YAQOOB, 1999; NEWSHOLME, 2001; LI et al. 2007; JIANG et al. 2009).

Atualmente, algumas pesquisas tem demonstrado alguns efeitos benéficos da inclusão de glutamina sobre o desempenho de suínos (YI et al. 2005; KITT et al. 2003 e 2004) em aves (SOLTAN, 2010; BARTEL \& BATAL, 2007; MAIORKA et al. 2000) e também em peixes (SILVA et al. 2010), além de diversos estudos na área médica como fisiologia do esporte, queimaduras, tratamento de doenças (BARBOSA, et al. 2003; MOTTA NETO, R. et al. 2007; SACKS, 2011; PELLEGRINOTTI et al. 2012). Entretanto a glutamina pode agir como tampão, aceitando a amônia excessiva e quando necessário formar 
outros aminoácidos, amino-açúcares, glicose, proteínas, nucleotídeos e ureia (RENNIE, 2001).

\section{O metabolismo da glutamina no organismo animal}

O metabolismo da glutamina acontece por uma única reação catalisada por duas enzimas, ou seja, a glutamina sintetase catalisa a síntese de glutamina fazendo a interação de glutamato e amônia e a glutaminase faz a reação inversa, catalisando a hidrólise da glutamina em glutamato e íon amônio, assim, a direção e os valores desta reação irão determinar se o tecido é consumidor ou produtor de glutamina (BULUS et al. 1989; CRUZAT et al. 2009). A síntese da glutamina acontece primariamente nos músculos, mas também nos pulmões, fígado, cérebro e possivelmente no tecido adiposo (ROWBOTTOM et al. 1996). Os rins, células do sistema imune e trato gastrointestinal usam a glutamina como substrato energético, enquanto o fígado é o único órgão que tanto a utiliza como a produz (NEWSHOLME, 1994).

Devido à utilização de proteínas para a construção de tecidos, estruturas variadas e enzimas (GUYTON, 2002) e aproximadamente $80 \%$ da glutamina corporal é encontrada no músculo esquelético, e esta concentração é 30 vezes maior do que no plasma (ROGERO et al. 2003) fica evidente que a glutamina atua na síntese protéica e na construção de tecido muscular.

A glutamina participa de várias vias metabólicas como na síntese de açúcares-aminados, tendo como principais exemplos as bases purinas e pirimidinas, que possuem participação no sistema energético bioquímico, pois purinas e pirimidinas fazem parte de moléculas de ATP, NADH e Coenzima A substâncias que participam diretamente do Cíclo do Ácido Cítrico ou Ciclo de Krebs (PANDE \& BLANCHEAR, 1971; MAO et al. 2003). A síntese de purinas, pirimidinas e de açúcares aminados, ocorre no citoplasma, enquanto que 0 metabolismo do esqueleto de carbono da glutamina é iniciado na mitocôndria por desaminação pela glutaminase dependente de fosfato (CURTHOYS e WATFORD, 1995). 
É importante na gliconeogênese (síntese de glicogênio) já que a glutamina tem a capacidade de elevar a atividade da enzima glicogênio sintetase favorecendo a formação de glicogênio hepático (FORTI, et al. 2003), além de que a glutamina é convertida em glutamato e este participa da produção de metabólitos como o piruvato, oxaloacetato, substâncias importantes para a gliconeogênese, glicólise ou o ciclo dos ácidos tricarboxílicos, tendo importante função no metabolismo energético, podendo ainda induzir a síntese de glicose pela via anaeróbica no músculo por provável ativação do Ciclo Malato-Aspartato (BARBOSA et al. 2003; MAO et al. 2003) síntese de uréia já que esta é o principal produto do catabolismo das proteínas em animais carnívoros e onívoros o que teoricamente é influenciado pela dieta protéica (OLIVEIRA JúNIOR, 2008), homeostase do pH, neurotransmissão, diferenciação e crescimento celular, sendo o principal substrato energético de células de proliferação rápida, como enterócitos intestinais e linfócitos ativados (CYNOBER, 1999) e ainda aumenta a resposta linfocítica à estimulação de mitógenos (TAUDOU et al. 1983).

A glutamina pode agir como tampão, aceitando a amônia excessiva e quando necessário aceitar outros aminoácidos, amino-açúcares, glicose, proteínas, nucleotídeos e ureia (SOUBA, 1993; RENNIE, 2001), SOLTAN (2010) ressalta que esta capacidade de aceitar nitrogênios doados faz da glutamina o maior veículo para a transferência de nitrogênio entre os tecidos. Além disso, o glutamato também tem importante ação no lugar da glutamina, como relata WU et al. (1995), afirmando que o glutamato pode substituir a glutamina em diversos papéis metabólicos, como na geração de energia e síntese de aminoácidos.

Importância fisiológica da glutamina em porcas no período de lactação

\section{Redução do catabolismo durante a lactação}

Segundo MEIJER et al. (1995), a mudança na concentração dos aminoácidos musculares, no período da gestação para a lactação, é uma 
característica que se descreve como estado catabólico nos mamíferos, em que a proteína muscular foi degradada para a suplementação de aminoácidos para a produção de leite. E o tamanho da leitegada também pode influenciar a intensidade do catabolismo como atestado por KIM \& EASTER (2001) que estudaram a mobilização de nutrientes em função do número de leitões, onde verificaram que o percentual de gordura na carcaça era maior nas matrizes com 9 leitões do que naquelas com 12 leitões, indicando grande influência da intensidade de suporte da leitegada pela fêmea. A glutamina apresenta efeito positivo na aceleração do turnover do carbono muscular, hepático e pancreático, indicando estímulo anabólico sobre estes tecidos (CALDARA et al. 2008).

CLOWES et al. (2005) em estudo sobre a mobilização proteica durante a lactação de porcas, observaram que o aumento acentuado de glutamina muscular livre nas porcas no final da lactação está relacionada com a perda proteica, sugerindo alta oferta de glutamina, confirmada com as observações das concentrações de glutamina no plasma que também aumentaram até o final da lactação.

O consumo de ração de matrizes suínas é sempre insuficiente para suprir os requerimentos nutricionais para produção de leite, e as reservas corporais podem ser parcialmente esgotadas, resultando em problemas reprodutivos subsequentes (QUINIOU \& NOBLET, 1999), segundo CLOWES et al. (2005), no final da lactação as perdas de massa muscular podem chegar a $36 \%$ com base no peso do dia do parto, entretanto, WU (2005) concluiu que uma suplementação de glutamina durante a lactação poderia prevenir a perda da massa muscular das matrizes suínas; já que a glutamina e o glutamato, mesmo representando de 10 a $15 \%$ do total de aminoácidos em muitos alimentos e coprodutos industriais (LI et al. 2010) e o milho e a soja não fornecerem um padrão ideal de amino ácidos para porcas em lactação.

Mesmo como aminoácido não-essencial, em situações de estresse a demanda por glutamina pode superar a sua capacidade de síntese, tornando sua suplementação relevante (LOPES, 2005), pois as concentrações de 
glutamina plasmática e muscular declinam ocasionando aumento do fornecimento de glutamina do músculo para outras regiões do corpo (CALDER \& NEWSHOLME, 2002).

Em estudo realizado por AQUINO (2012) a suplementação de 1,5\% de Aminogut (L-Glutamina mais Ácido L-Glutâmico livres na proporção de 1:1) na dieta de porcas lactantes resultou na perda de apenas $1,98 \%$ ao final de 21 dias de lactação, já as matrizes que não tiveram a inclusão de Aminogut na dieta perderam em média $11,07 \%$ da massa corporal. A perda de peso por matrizes suínas corresponde a depleção das porções protéica e lipídica, de acordo com CLOWES et al. (2003) o catabolismo lactacional reduz cerca de $11 \%$ da massa protéica, e justamente por isso, a dieta deve garantir um mínimo de tecido magro contra os efeitos do catabolismo lactacional.

\section{Melhoria da performance reprodutiva}

JOHNSTON et al. (1993) afirmaram que a perda de proteína corpórea durante a lactação pode ter uma maior influência na performance reprodutiva subsequente do que na perda de gordura corporal. JONES \& STAHLY (1999) afirmaram que a excessiva mobilização de proteína materna sempre resulta em falha reprodutiva para a próxima parição. Já CLOWES et al. (2003) avaliando a perda de massa muscular em porcas primíparas durante a lactação no desempenho reprodutivo verificaram que as matrizes com melhor massa corporal ao desmame apresentam folículos maiores, acima de 3,5 $\mathrm{mm}$ de diâmetro e que terão retorno ao próximo cio mais rápido do que aquelas que tiveram menor massa corporal ao desmame, consequentemente folículos com diâmetro menor do que $3,5 \mathrm{~mm}$ o que poderá resultar em maior tempo de retorno ao cio.

AQUINO (2012) verificou que o retorno ao cio de porcas que não receberam dietas com $1,5 \%$ de Aminogut apresentaram retorno ao cio tardio em 22 dias, o que, no estudo está associado à perda de massa corporal durante a lactação de porcas criadas intensivamente na Zona da Mata do estado de Pernambuco, com clima prevalente no período experimental de $22^{\circ} \mathrm{C}$ 
a $34^{\circ} \mathrm{C}$ e umidade relativa do ar de $42,9 \%$ a $96,7 \%$. Além das perdas corporais afetarem o desempenho reprodutivo das matrizes por comprometerem entre outros fatores o intervalo desmame-cio (CLOWES et al. 2003; LIMA et al. 2011) os fatores ambientais também podem influenciar as características reprodutivas e produtivas dos suínos, como afirmou CAVALCANTE NETO et al. (2008).

\section{Fortalecimento do sistema imune}

Durante a lactação os principais problemas apresentados pelas matrizes neste estágio fisiológico são aqueles relacionados à condição sanitária dos úberes, pois apesar de não ser tão perceptível e não receber a devida atenção, a mastite, afeta porcas em todas as regiões do mundo e desempenha um papel importante na Síndrome da Hipoagalaxia do Periparto - SHP (ZHU, 2007), que geralmente acomete os animais imediatamente após o parto, com alto risco nas primeiras três semanas de lactação, quando a produção de leite aumenta ocorrendo associada à metrites e agalaxia, os efeitos consistem na redução e significativa alteração da secreção de leite (PERSSON et al. 1989; OGNEAN et al. 2010), sendo causada por patógenos gram-negativos disseminados nas fezes, como Escherichia coli (E. Coli), Klebsiella pneumoniae (K. Pneumoniae) e várias espécies de Enterobacter,os quais, constituem os mais comuns patógenos vinculados às mastites coliformais (RINGARP, 1960), tendo como principal contribuinte a constante amamentação, que não ocorre com vacas leiteiras (GARST et al. 1999), e considerando que o focinho suíno, por ser um órgão tátil, desempenha um importante papel como vetor de microrganismos do ambiente, mais precisamente do piso contaminado por fezes, para as tetas das porcas. As infecções mamárias influenciam o conteúdo de células somáticas no leite.

Normalmente, o conteúdo de células somáticas no leite de porcas é muito alto, as quais, são constituídas por células do sistema imune e epiteliais, com uma CCS entre 1 e 4 milhões de células por mililitro em porcas saudáveis (HURLEY \& GRIEVE, 1988), onde as subpopulações celulares no leite de porcas 
apresentam configuração característica com a predominância de macrófagos $(40,87 \%)$, seguido por linfócitos $(31 \%)$, leucócitos $(15,8 \%)$ e por células epiteliais (12,33\%), OGNEAN et al. (2010).

Atualmente a contagem de células somáticas (CCS) é o principal indicador de mastite bovina e reflete a resposta de combate à doença pelo animal, porém, os testes desenvolvidos para vacas não são recomendados para porcas devido a grande diferença entre as altas concentrações de células somáticas no leite destas para a reduzida concentração no leite bovino (ZHU, 2007), porém, acredita-se que a condutividade elétrica e o exame citológico podem dar resultados conclusivos sobre a incidência de mastites em porcas (OGNEAN et al. 2010).

A glutamina é importante para o fortalecimento da imunidade, e para a produção protéica extracelular (fibras musculares) e intracelular (síntese de DNA e RNA) e ainda atua como uma fonte alternativa de energia, por participar na produção de ATP, pelo aporte energético às células (leucócitos, enterócitos, etc.) promovendo a proliferação e desenvolvimento desses grupos celulares (ROTH, 2008; WU, 2010).

AQUINO (2012) verificou o aumento da CCS no leite de porcas que foram alimentadas com dietas acrescidas de $1,5 \%$ de Aminogut, resultando em acréscimos percentuais de $55,57 \%$ no leite aos 7 dias de lactação e de 39,09\% no leite aos 21 dias de lactação, e atribuiu o aumento do conteúdo de CCS no leite ao fato de a glutamina servir como substrato energético das células imunológicas e estas se proliferarem para auxiliar no controle das infecções mamárias.

\section{Melhoria da qualidade do leite}

A composição do leite de porca pode ser influenciada pela suplementação de glutamina, uma vez que este aminoácido participa direta e indiretamente do metabolismo da proteína, dos lipídios e dos açúcares e influencia os sólidos totais. Além de participar na proliferação de células do sistema imunológicos 
(WALLACE \& KEAST 1992, OGLE et al. 1994) tão importantes no início da lactação, quando o colostro comporta grande conteúdo de imunoglobulinas.

KOWALCHUK et al. (1988) ao afirmar que, se as condições para lipogênese e formação de triacilglicerol são favoráveis, a maior parte da glutamina removida pelo tecido adiposo é convertida em glutamato que, posteriormente, é metabolizado para acetil-CoA, como precursor para a lipogênese. Segundo YOO et al. (2008) a glutamina é o maior precursor para o carbono lipogênico, suprindo mais unidades de Acetil-CoA do que a glicose ou outra fonte sozinha. AQUINO (2012) verificou que o no colostro e no leite colhido aos 7 dias e aos 21 dias de lactação houve um aumento no percentual de gordura de $2,74 \%, 0,34 \%$ e de $2,10 \%$, respectivamente e que o conteúdo de gordura foi mantido em todo o período de lactação, diferentemente das porcas do grupo Controle que apresentaram depleção do conteúdo de gordura entre o sétimo dia até o desmame ( 21 dias) de $26,9 \%$.

$\mathrm{Na}$ transição do colostro para o leite é notável uma diminuição do conteúdo protéico e isso se deve ao fato de o colostro ser rico em imunoglobulinas, e a maior perda de proteína do colostro ao leite no sétimo dia se deve ao maior conteúdo protéico no colostro do grupo Aminogut (KLOBASA, 1987; ELLIOTT, 1971; FHAMY, 1972; RICALDE \& LEAN, 2000; AQUINO, 2012).

O percentual de Sólidos Totais, que é constituído pelos teores de gordura, proteína e lactose, é influenciado pela suplementação de glutamina, visto que influencia fortemente o percentual de gordura e proteína do leite (AQUINO, 2012). Com a suplementação de 1,5\% de Aminogut na dieta de porcas lactantes AQUINO (2012) verificou que ocorreu uma elevação do conteúdo de sólidos totais no colostro e no leite de 1,74\% e de 1,30\%, respectivamente, e que as matrizes do grupo Controle apresentaram diminuição do conteúdo de sólidos totais de $1,68 \%$ na passagem do colostro para o leite aos sete dias, o que não foi observado nas fêmeas que alimentadas com rações contendo Aminogut por causa, principalmente, do aumento no conteúdo de gordura. 
O aumento da concentração de glutamina e de glutamato no leite de porcas foi verificada por MANSO (2012) onde atestou aumento de $110 \%$ de glutamina no leite de matrizes suínas suplementadas com Aminogut, e um aumento de $240 \%$ na concentração de glutamina mais glutamato no leite aos 21 dias, em avaliação da suplementação de 2,5\% de Aminogut por quilograma de ração consumida. Já, AQUINO (2012), verificou que o aumento de 1,5\% de Aminogut na dieta de porcas em lactação acresceu o conteúdo de glutamina livre no leite aos 21 dias de lactação em $62,40 \%$ e aumento no conteúdo de glutamina mais glutamato de 50,95\%, também aos 21 dias de lactação.

\section{O reflexo da suplementação de glutamina às porcas no desenvolvimento da leitegada}

De acordo com o aumento do conteúdo de gordura, proteína, sólidos totais, e de glutamina e glutamato livres no colostro e no leite (AQUINO, 2012; MANSO, 2012) e dos benefícios fisiológicos da glutamina como a proliferação de células imunológicas e das células intestinais AQUINO (2012) verificou aumento de $8,87 \%$ no peso de leitões desmamados de porcas que receberam $1,5 \%$ de Aminogut na dieta de lactação durante os 21 dias de lactação.

Segundo YOO et al. (1997) quando leitões estão expostos a infecção moderada, a suplementação de glutamina mantém normal a concentração da glutamina muscular intracelular, as populações leucocitárias e as funções dos linfócitos. O fortalecimento da imunidade do leitão associado com a aceleração do desenvolvimento das vilosidades intestinais e proliferação dos enterócitos promovem em conjunto a diminuição da mortalidade de leitões pós-desmame, além disso, o efeito catabólico causado pela situação de estresse ou por doenças é diminuído, conferindo a importância da utilização da glutamina nas fases de gestação, lactação e pós-desmame. 


\section{CONCLUSÃO}

O aporte extra de glutamina na dieta de matrizes suínas em lactação contribui com diversos aspectos produtivos, como:

1. A manutenção da massa corporal, pela diminuição dos efeitos catabólicos presentes nos estágios fisiológicos de gestação e de lactação;

2. Com a manutenção do peso vivo das fêmeas possibilita-se melhoria das condições reprodutivas seguintes ao desmame;

3. Melhoria da qualidade do colostro e do leite, pela maior síntese de proteínas, gorduras e sólidos totais, além de prover colostro com maior aporte de imunoglobulinas, e possibilitar maior concentração de glutamina e glutamato livres no leite;

4. Promove melhor condição produtiva de leitões devido ao suprimento das necessidades da leitegada pelo maior aporte de nutrientes como a gordura (necessária para o suprimento energético, principalmente para a manutenção da temperatura do corpo), a proteína (maior aporte de proteínas para desenvolvimento tecidual, aumento de peso e fortalecimento do sistema imunológico), glutamina e glutamato livres (importantes para o desenvolvimento dos enterócitos e sistema imune), contribuindo para melhores condições de adaptação ao desmame.

\section{REFERÊNCIAS}

ABREU, M. L. T. et al. Glutamina, nucleotídeos e plasma suíno em rações para leitões desmamados. Revista Brasileira de Zootecnia, v.39, n.3, p.520-525, 2010.

AQUINO, R.S. Efeito da glutamina em matrizes suínas lactantes. 2012. 76f. Dissertação de Mestrado - Programa de Pós-Graduação em Zootecnia, Universidade Federal Rural de Pernambuco, PE.

BARBOSA, R.C.C. et al. Efeitos metabólicos da glutamina em ratos submetidos à queimadura por água fervente (escaldadura). Acta Cirúrgica Brasileira, vol. 18, n.6, p. 527-533, 2003.

BARTEL, S.M.; BATAL, A.B. The effect of supplemental glutamine on growth performance, development of the gastrointestinal tract, and immune response of broilers. Poultry Science, vol. 86, p. 1940 - 1947, 2007.

BULUS, N. et al. Physiological importance of glutamine. Metabolism, New York, v.38, p. 1 - 5, Supplement 1, 1989. 
CALDARA, F. R. et al. Efeito da glutamina sobre o turnover do carbono $\left(\mathrm{d}^{13} \mathrm{C}\right)$ de músculos e vísceras de leitões desmamados: glutamina e turnover de carbono tecidual. Acta Scientiarum Animal Sciences. Maringá, v. 30, n. 3, p. 291-297, 2008.

CALDER, P.C.; NEWSHOLME, P. Glutamine and the immune system, In: P.C. CALDER; C.J. FIELD; H.S. GILL. Nutrition and Immune Function, p.109-133, 2002.

CALDER, P.C.; YAQOOB, P. Glutamine and immune system. Amino Acids, v. 17, n. 1, p. 227 $241,1999$.

CAVALCANTE NETO, A. et al. Efeitos genéticos e ambientais sobre a idade à primeira concepção fêmeas suínas. Arquivo Brasileiro de medicina Veterinária e Zootecnia, vol. 60, n. 2, p. $499-502,2008$.

CLOWES, E.J. et al. Selective protein loss in lactating sows is associated with reduced litter growth and ovarian function. Journal of Animal Science, v. 81, p. 753 - 764, 2003.

CLOWES, E.J. et al. Skeletal muscle protein mobilization during the progression of lactation. Journal of Physiology Endocrinology Metabolism, v. 288, E564 - E572, 2005.

CRUZAT, V.F. et al. Glutamina: aspectos bioquímicos, metabólicos, moleculares e suplementação. Revista Brasileira de Medicina do Esporte, vol. Vol. 15, n. 5, p. 392-397, 2009.

CURTHOYS, N. P. e WATFORD, M. Regulation of glutaminase activity and glutamine metabolism. Annual Review of Nutrition, v. 15, p. 133-159, 1995.

CYNOBER, L. A. Glutamine metabolism in stressed patients (Abstract). In: $6^{\text {th }}$ Proceedings of International Congress on Amino Acids. Bonn, 1999, p. 5.

ELLIOT, R.F. et al. Effect of dietary protein level on composition changes in sow colostrums and milk. Journal of Animal Science, vol. 32, n. 6, p. 1128 - 1137, 1971.

FAHMY, M.H. Comparative study of colostrums and milk composition of seven breeds of swine. Canadian Journal of Animal Science, vol. 52, n. 4, p. 621 - 627, 1972.

FORTI, F. et al. O efeito da glutamina no músculo esquelético desnervado. Saúde em Revista, v.9, p.59-65, 2003.

FORTI, F.L. Clonagem do receptor de ACTH de células adrenocorticais Y-1 de camundongo e expressão em fibroblastos 3T3 e células AR-1 para elucidação das vias de transdução de sinal. 2001. Tese (Doutorado)-Universidade de São Paulo, São Paulo, 2001.

GARST, A.S. et al. Influence of machine milking of sows on lactetional milk yield and litter weights. Journal of Animal Science. Vol. 77, p. 1620-1623, 1999.

GUYTON, A. Fisiologia humana. 10a ed. 2002. Rio de Janeiro: Guanabara Koogan.

HLASIWETZ \& HABERMANN. A glutinamic acid form animal proteic matters. Chemical News and Journal of Physical Science. vol. 28, p. 21, 1873. Disponível em: http://books.google.com.br/books?id=zfnmAAAAMAAJ\&pg=PA21\&lpg=PA21\&dq=hlasiwetz+ha bermann $+1873 \&$ source $=$ bl\&ots $=$ rRTEpub38X\&sig =bx5MkjBND6jkiyIE40E0qJaPSdc\&hl=pt-

R\&sa $=X \& e i=$ DC5uT4mKOozAgQfC3ulr\&ved=0CFUQ6AEwBg\#v=onepage\&q=hlasiwetz\%20habe rmann\%201873\&f=false Acessado em: 21/10/2011

HURLEY, W.L.; GRIEVE, R.C.J. Total and differential cell counts and N-acetyl-B-Dglucosaminidase activity in sow milk during lactation. Veterinary Research Communications, vol. 12, n. 2-3, p. $149-153,1988$.

JIANG, Z.Y. et al. Effects of dietary glycyl-glutamine on growth performance, small intestinal integrity, and immune responses of weaning piglets challenged with lipopolysaccharide. Journal of Animal Science, vol. 87, p. 4050 - 4056, 2009. 
JOHNSTON, L.J.; PETTIGREW, J.E.; RUST, J.W. Response of maternal-line sows to dietary protein concentration during lactation. Journal of Animal Science. vol. 71, p. $2151-2156$. 1993.

JONES, D. B.; T. S. STAHLY. Impact of amino acid nutrition during lactating on body nutrient mobilization and milk nutrient output in primiparous sows. Journal of Animal Science. vol. 77, p. 1513 - 1522. 1999.

KIM, S.W. et al. Functional Amino acids and fatty acids for enhancing production performance of sows and piglets. Asian-Australasian Journal of Animal Science, vol. 20, n.2, p. 295 306, 2007.

KIM, S.W.; \& EASTER, R.A. Nutrient mobilization from body tissues as influenced by litter size in lactating sows. Journal of Animal Science, vol. 79, p. 2179 - 2186, 2001.

KIM, S.W.; WU, G. Regulatory role for amino acids in mammary gland growth and milk synthesis. Amino Acids, vol. 37, n. 1, p. 89 - 95, 2009.

KITT, S.J. et al. Effects of glutamine on growth performance and intestinal development of immune challenged wealing pigs fed chemically defined diets. Nebraska Swine Report, p. 34 - 38, 2003.

KLOBASA, F. et al. Composition of sow milk during lactation. Journal of Animal Science, vol. 64, p. 1458 - 1466, 1987.

KOWALCHUK, J.M. et al. Glutamine metabolism in isolated incubated adipocytes of the rat. Biochemical Journal, vol.249, p.705-708, 1988.

KREBS, H.A. Metabolism of amino acids IV. The synthesis of glutamine from glutamic acid and amonia, and the enzymatic hydrolysis of glutamine in animal tissues. Journal of Biochem; vol. 33, p. 1951 - 1969, 1935.

$\mathrm{LI}$, X. et al. Composition of amino acids in feed ingredients for animal diets. Amino Acids, vol. 40, p. 1159 - 1168, 2010.

LIMA, A.L. et al. Resfriamento do piso da maternidade para porcas em lactação no verão. Revista Brasileira de Zootecnia, vol. 40, n. 4, p. 804 - 811, 2011.

LOPES, P.F.; Efeitos da glutamine sobre a parede intestinal e sua aplicabilidade potencial em coloproctologia. Revista Brasileira de Coloproctologia, vol. 25, no. 1, p. 75 - 78, 2005.

MAIORKA, $A$. et al. Influência da suplementação de glutamina sobre o desempenho e o desenvolvimento de vilos e criptas do intestino delgado de frangos. Arquivo Brasileiro de Medicina Veterinária e Zootecnia. vol. 52, n. 5, 2000.

MANSO, H.E.C.C.C. et al. Glutamine and glutamate supplementation raise milk glutamine concentrations in lactating gilts. Journal of Animal Science and Biotechnology, vol.3, n.2, 2012. Doi: $10.1186 / 2049-1891-3-2$.

MAO, L. et al. Multiple intermolecular interaction modes of positively charged residues with adenine in ATP-binding proteins. Journal of American Chemistry Society, vol. 125, n. 47, p. $14216-14217,2003$.

MEIJER, G.A.L. et al. Free amino acids in plasma and muscles of high yielding dairy cows in early lactation. Journal of Dairy Science, vol. 78, p. 1131 - 1141, 1995.

MOTTA NETO, R. et al. Glutamine or whey-protein supplementation on alloxan-induced diabetic rats. Acta Cirúrgica Brasileira, vol. 22, n.3, p. 215-219, 2007.

NEWSHOLME, E. A. Biochemical mechanisms to explain immunossupression in well-trained and over trained athletes. International Journal Sports Medicine, vol. 15, p. 142 - 147, 1994.

NEWSHOLME, E. A. Biochemical mechanisms to explain immunossupression in well-trained and over trained athletes. International Journal Sports Medicine, vol. 15, p. 142 - 147, 1994. 
NEWSHOLME, P. Why is L-glutamine metabolism important to cells of the immune system in health, postinjury, surgery or infection? Journal of Nutrition, vol. 131, p. 2515S - 2522S, 2001.

NOBLET, J.; ETIENNE, M. Estimation of sow milk nutrient output. Journal of Animal Science, vol. 67, p. $3352-3359,1999$.

OGLE, C. K. et al. Effect of glutamine on phagocytosis and bacterial killing by normal and pediatric burn patient neutrophils. Journal of Parenteral and Enteral Nutrition, vol. 18, p. 128 - 133, 1994.

OGNEAN, L. et al. The evolution of the hemogram and certain parameters from blood and milk of sows during the first week post-partum. Bulletin UASVM, Veterinary Medicine vol. 67, no. 1 / 2010. ISSN 1843-5270; Eletronic ISSN 1843-5378. Disponível em: <http://journals.usamvcj.ro/veterinary/article/viewFile/5941/5430>Acesso em: 03/10/2011.

OLIVEIRA JÚNIOR, A. R. Glutamina, ácido glutâmico e ou extrato de levedura na dieta de leitões desmamados. 2008. 67f. Dissertação de mestrado - Universidade Federal de Uberlândia, MG.

PANDE, S.V.; BLANCHAER, M.C. Reversible inhibition of mitochondrial adenosine diphosphate phosphorilation by long chain acyl coenzyme A esters. The Journal of Biological Chemistry, vol. 246, no 2, p. $402-411,1971$.

PELLEGRINOTTI, I.L. et al. Efeito da suplementação oral de glutamina na performance de nadadores de meiofundo e fundo. Pensar a Prática, vol. 15, n. 2, p. 272-505, 2012.

PERSSON, A. et al. A long term study of the health status and performance of sows on different feed allowances during late pregnancy. I. Clinical observations, with special reference to agalactia post-partum. Acta Veterinarian Scandinavian vol. 30, p. 9 - 17, 1989.

QUINIOU, N.; \& NOBLET, J. Influence of high ambient temperatures on performance of multiparous lactating sows. Journal of Animal Science, vol. 77, p. 2124 - 2134, 1999.

RENNIE, M.J et al. Interaction between glutamine availability and metabolism of glycogen, tricarboxylic acid cycle intermediates and glutathione. Journal of Nutrition, vol.131, p.24882490, 2001.

RINGARP, N. Clinical and experimental investigations into a post-parturient syndrome with agalactia in sows. Acta Agriculturian Scandinavian Suppl. Vol. 7, n.1, 1960.

ROGERO M.M.; TIRAPEGUI, J. Considerações nutricionais e bioquímicas da suplementação de glutamina em atletas: controvérsias e aspectos atuais. Journal of Nutrition, vol. 7, p. 106 17, 2003.

ROTH, E. Nonnutritive effects of glutamine. The Journal of Nutrition, vol. 138, p. $2025 \mathrm{~S}-$ 2031S, 2008.

ROWBOTTOM D.G. et al. The emerging role of glutamine as an indicator of exercise stress and overtraining. Sports Medicine, vol. 21, p. 80 - 97, 1996.

SACKS, G.S. Effect of glutamine-supplemented parenteral nutrition on mortality in critically ill patients. Nutrition in clinical practice, vol. 26, n.1, p. 44-47, 2011.

SILVA, L.C.R. et al. Desempenho e morfometria intestinal de juvenis de tilápia-do-nilo alimentados com dietas suplementadas com L-glutamina e L-glutamato. Revista Brasileira de Zootecnia, vol. 39, n. 6, p. $1175-1179,2010$.

SOLTAN, M.A. Influence of dietary glutamine supplementation on growth performance, small intestinal morphology, immune response and some blood parameters of broilers chickens. International Journal of Poultry Science, vol.8, n.1, p. $60-68,2010$.

SOUBA, W.W. Glutamine and cancer. Annals of Surgery, vol. 218, p.715-728, 1993. 
TAUDOU, G. et al. Influence of amino acid deficiency and tRNA aminoacylation on DNA synthesis and DNA polymerase activity during secondary immune response in vitro. Molecular Immunology, vol. 20, n. 3, p. 255 - 261, 1983.

UNITED STATES DEPARTMENT OF AGRICULTURE (USDA) - DIETARY GUIDELINES ADVISORY COMITTEES (DGAC), 2010. Report of the DGAC on the Dietary Guidelines for Americans, 2010. Part D, Section 4: Protein. Disponível em: http://www.cnpp.usda.gov/DGAs2010DGACReport.htm . Acessado em: 22/04/2012.

WALLACE, C. \& KEAST, D. Glutamine and macrophage function. Medicine Clinical Experimental vol. 41, p. 1016 - 1020, 1992.

WATFORD, M. et al. Optimal dietary glutamine for growth and development. Revista Brasileira de Zootecnia, vol. 40, p. 384 - 390, 2011.

WATFORD, M. Glutamine metabolism and function in relation to proline synthesis and the safety of glutamine and proline supplementation. The Journal of Nutrition, vol. 138, p. $2003 S$ - 2007S, 2008.

WU, G. et al. Branchedchain amino acid in lactating porcine mammary tissue. Federation of American Societies for Experimental Biology - FASEB - Journal, vol. 19, A985, 2005 b.

WU, G. et al. Glutamine and glucose metabolism in enterocytes of the neonatal pig. American Journal of Physiology, vol. 268, n. 2, p. 334 - 342, 1995.

WU, G. et al. Important roles for the arginine family of amino acids in swine nutrition and production. Livestock Science, vol. 112, p. 8 - 22, 2007.

WU, G. Functional amino acids in growth, reproduction, and health. Advances in Nutrition, vol. 1, p. $31-37,2010$.

YI, G.F.; CARROL, J.A.; ALEE, G.L. et al. Effect of glutamine and spray-dried plasma on growth performance, small intestine morphology, and immune responses of Escherichia coli $\mathrm{K} 88+$ challenged weaned pigs. Journal of Animal Science, vol.83, p. $634-643,2005$.

YOO, $\mathrm{H}$. et al. Quantifying reductive carboxilation flux of glutamine to lipid in a brown adipocyte cell line. Journal of Biological Chemistry, vol. 283, p. 20621 - 20627, 2008.

YOO, S. S. et al. Glutamine supplementation maintains intramuscular glutamine concentration and normalize lymphocyte function in infected early weaned pigs. The Journal of Nutrition. vol. 127, n. 11, p. $2253-2259,1997$.

$\mathrm{ZHU}, \mathrm{Y}$. Early inflammatory response in periparturient sows to experimentally induced Esccherichia coli mastitis special reference to cytokine responses. Doctoral thesis, Swidesh University of Agricultural Sciences. Uppsala 2007. Acta Universitatis Agriculturae Sueciae. 2007 : 98. ISSN 1652-6880; ISBN 978-91-576-7397-8. 